\title{
Study of Solubility and Speciation of Iron Sulfates in Phosphoric Acid Milieu "5.5-14 Mole"
}

\author{
Sara ELJAOUHARI ${ }^{1}$, Mouna L. BOUAMRANI ${ }^{2}$, H. ARGANI $^{3}$, Samia YOUSFI $^{4}$ \\ Département de Chimie, Faculté des Sciences Ben M'Sik, Laboratoire de Chimie Analytique et Physico-Chimie des Matériaux, Université \\ HASAN II de Casablanca
}

\begin{abstract}
Industrial phosphoric acid contains free metal impurities and / or complexed one. Moreover, each element of the chemical forms and each proportion's form are still unknown. However, the total contents of each element have been known up to now. It is necessary restraining the elimination or recuperation of the species in solution, to understand their deportment and know what form they may exist. This work examin the behavior and speciation of iron sulfate's ions by monitoring the kinetics reaction of the iron sulfate's dissociation in the phosphoric acid in various capacities $(5.5-14,7 M)$ and by the characterization of the product precipitated by the ray $X$ diffractions. The results obtained have allowed us to determine the equilibrium time of the dissociation reaction of iron sulfates in different phosphoric acid milieu at ambient temperature and the influence of acid content on the sulfate ions $\left(\mathrm{SO}_{4}{ }^{2-}\right)$ and iron II (Fe $\left.{ }^{2+}\right)$ behavior. This work allowed us to retain the following: The variation of the phosphoric acid content has significant influence on the equilibrium time of the dissociation reaction of the iron sulfates. The variation of the phosphoric acid content has no significant influence on the precipitated product nature. The precipitated structural analysis confirms the absence of iron phosphate $\left(\mathrm{Fe}_{3}\left(\mathrm{PO}_{4}\right)_{2}\right)$ and the compound obtained is always iron sulfates $\left(\mathrm{FeSO}_{4}\right)$.
\end{abstract}

Keywords: Speciation; Solubility; Speciation, Iron Sulfate; Phosphoric Acid; Solubilization.

\section{Introduction}

Phosphoric acid is a chemical compound that is of great importance at the industrial level because it intervenes in many applications such as, fertilizers phosphate manufacturing, treatment of metal surfaces, organic synthesis, detergents manufacturing, in food industries, etc.

Phosphoric acid is mainly obtained from phosphate rock by the wet process. The obtained phosphoric acid contains most of the impurities previously present in the ore [1].

The common impurities in the phosphate rock are aluminium $\left(\mathrm{Al}^{3+}\right)$, iron $\left(\mathrm{Fe}^{3+}\right)$, magnesium $\left(\mathrm{Mg}^{2+}\right)$, calcium $\left(\mathrm{Ca}^{2+}\right)$, potassium $\left(\mathrm{K}^{+}\right)$, strontium, chlorides $\left(\mathrm{Cl}^{-}\right)$and fluoride $\left(\mathrm{F}^{-}\right)$. Iron $\left(\mathrm{Fe}^{3+}\right)$ and aluminum $\left(\mathrm{Al}^{3+}\right)$ are often considered as the same category part of impurity. [2]

However phosphoric acid milieu remains very complex and not known enough.

This work examine the behavior and speciation of iron sulfate ions by monitoring the kinetics reaction of the iron sulfate dissociation in the phosphoric acid in various capacities ( $5.5-14 \mathrm{M}$ ) and by the characterization of the product precipitated by the ray $\mathrm{X}$ diffractions.

\section{Materials and Methods}

The dissociation reaction of iron sulfate was performed at ambient temperature and monitoring the kinetics performed by electronic thermometer until stabilization of the temperature of the mixture.

The equilibrium time of the reaction is calculated from the average of the equilibrium time of three similar tests.

$$
T e=\frac{\mathrm{Te} 1+\mathrm{Te} 2+\mathrm{Te} 3}{3}
$$

Te: Average time equilibrium

The residue precipitate is then filtered, washed with acetone and dried temperature at of $40^{\circ} \mathrm{C}$.

\section{Test Methods}

For the study of the resulting products we performed diffraction analysis X-ray to determine the crystal structure.

\section{Result and Discussion}

\subsection{Probable chemical reaction in the system studied}

Chemical reaction in the pur phosphoric acid milieu

$\mathrm{H}_{3} \mathrm{PO}_{4}+\mathrm{H}_{2} \mathrm{O} \Leftrightarrow \mathrm{H}_{2} \mathrm{PO}_{4}^{-}+\mathrm{H}_{3} \mathrm{O}^{+}$

$\mathrm{H}_{2} \mathrm{PO}_{4}^{-}+\mathrm{H}_{2} \mathrm{O} \Leftrightarrow \mathrm{HPO}_{4}{ }^{2-}+\mathrm{H}_{3} \mathrm{O}^{+}$

$\mathrm{HPO}_{4}{ }^{2-}+\mathrm{H}_{2} \mathrm{O} \Leftrightarrow \mathrm{PO}_{4}{ }^{3-}+\mathrm{H}_{3} \mathrm{O}^{+}$

Probable chemical reaction in the phosphoric acid milieu containing iron sulfates.

(1) $\mathrm{FeSO}_{4} \Leftrightarrow \mathrm{Fe}^{2+}+\mathrm{SO}_{4}^{2-}$

(2) $2 \mathrm{PO}_{4}{ }^{3-}+3 \mathrm{Fe}^{2+} \Leftrightarrow \mathrm{Fe}_{3}\left(\mathrm{PO}_{4}\right)_{2}$

(3) $2 \mathrm{H}_{3} \mathrm{PO}_{4}+3 \mathrm{FeSO}_{4} \Leftrightarrow \mathrm{Fe}_{3}\left(\mathrm{PO}_{4}\right)_{2}+3 \mathrm{H}_{2} \mathrm{SO}_{4}$

In the ion phosphoric milieu acid $\mathrm{SO}^{4-}$ ions have basic character [3] which results in the production of hydrogen ions $\mathrm{HSO}_{4}^{-}$:

$$
\mathrm{H}_{3} \mathrm{PO}_{4}+\mathrm{SO}_{4}^{-} \Leftrightarrow \mathrm{H}_{2} \mathrm{PO}_{4}^{-}+\mathrm{HSO}_{4}{ }^{-}
$$

Contrary to $\mathrm{SO}_{4}{ }^{2-}$ ions the hydrogen sulfate ions $\mathrm{HSO}_{4}{ }^{-}$are deprived of their basic character [3] and thus unable to capture protons to form sulfuric $\mathrm{H}_{2} \mathrm{SO}_{4}$ and therefore the acid reaction (3) is not moving in the direction of production of sulfuric acid and ferric phosphate. The precipitates XRD analysis confirms this hypothesis. (Figure 1 and 2) 


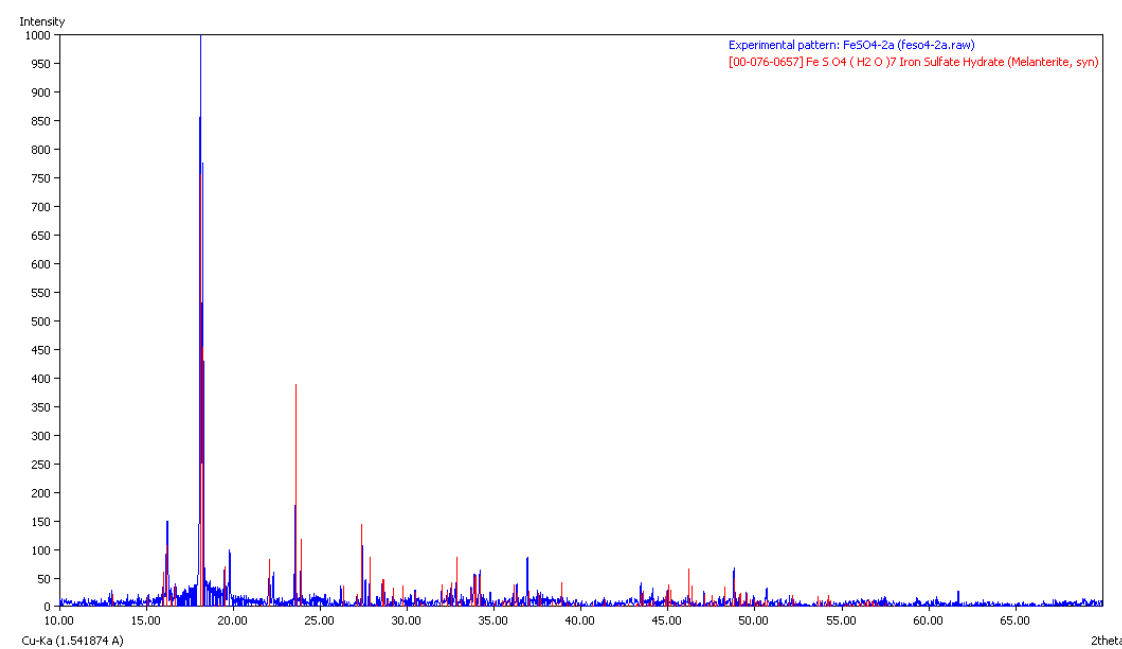

Figure 1: Spectrum Diffraction X-ray of the precipitated product of dissociation reaction of iron sulfate $14 \mathrm{M}$ phosphoric acid.

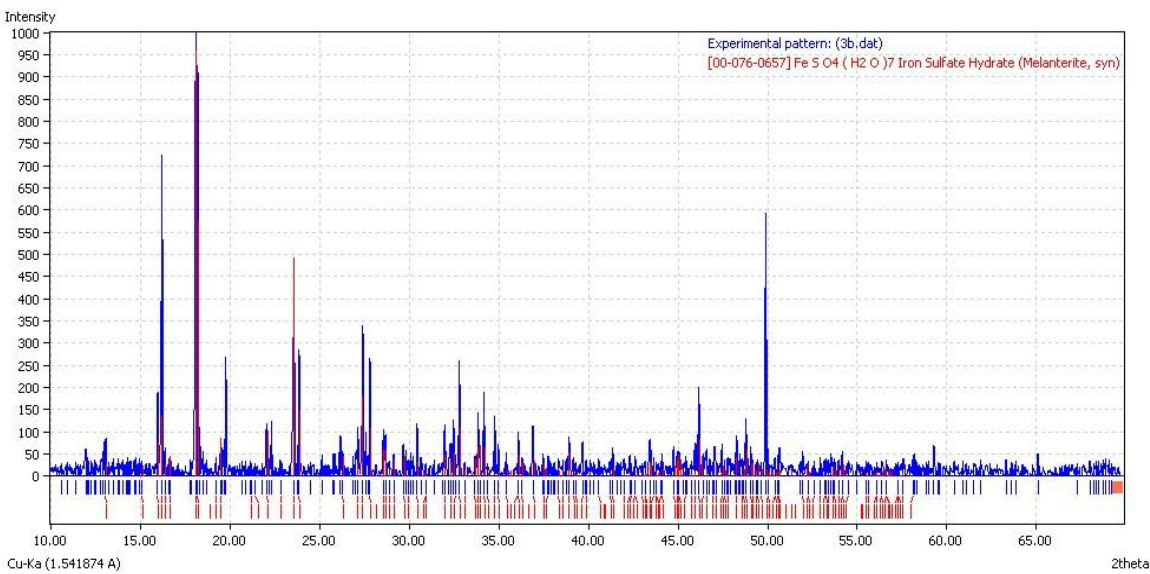

Figure 2: Spectrum Diffraction X-ray of the precipitated product of dissociation reaction of iron sulfate $5.5 \mathrm{M}$ phosphoric acid

\subsection{Equilibrium time of the reaction of solubility of the iron sulfate in the phosphoric acid milieu.}

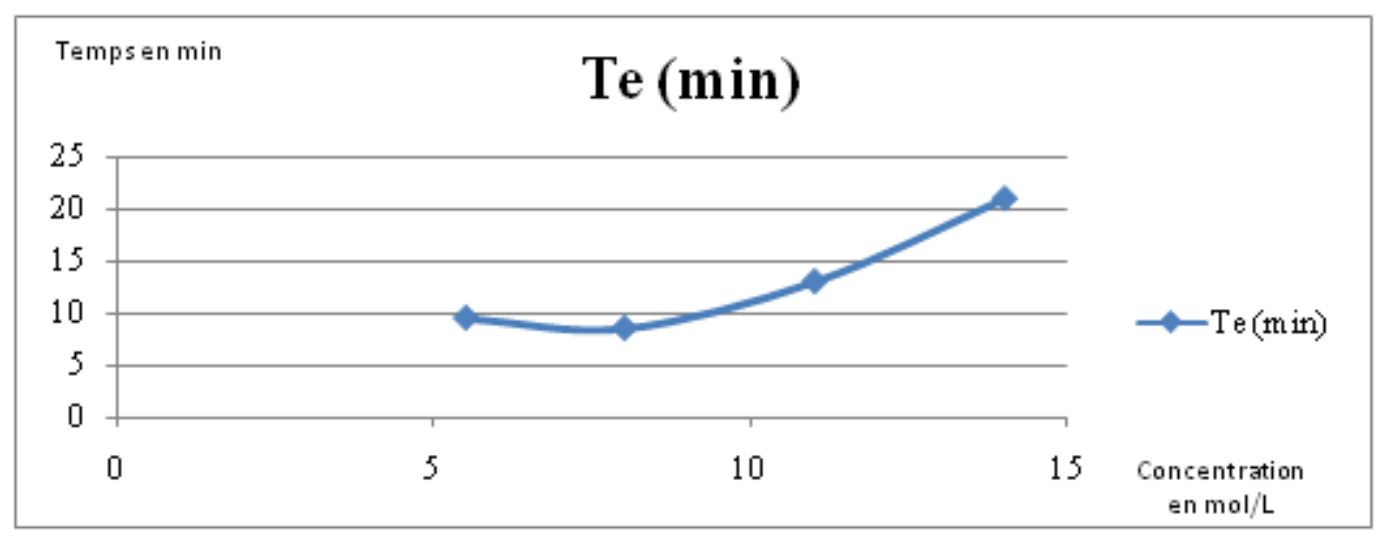

Figure 3: The dissociation reaction of iron sulfate equilibrium time in minutes in terms of the molar concentration of phosphoric acid

At a concentration of $5.5 \mathrm{M}$ phosphoric acid corresponding to the crude phosphoric acid obtained by a wet process [4]. Acid molecules well solvated fail to react with the entire iron sulfate [2] and therefore the solution is rapidly saturated and equilibrium time is equal to the equilibrium time of the dissociation reaction of iron sulfate in desiled water. [5]

In mid pure phosphoric acid solubilization of iron sulfate take more time ( 2 times the solubilization time in the water or in a solution concentration's close to that raw phosphoric acid $5.5 \mathrm{M}$ ) this can be explained by the decrease the amount of water in the pure phosphoric acid. Phosphoric acid molecules very little solvated react properly with the majority of iron sulphates and thus the reaction takes longer.

The more acid environment is more focus contact between the acid molecules and sulfates salt is better and the reaction is slow.

\section{Conclusion}

This work allowed us to retain the following:

\section{Volume 5 Issue 8, August 2016} www.ijsr.net 


\section{International Journal of Science and Research (IJSR) \\ ISSN (Online): 2319-7064}

Index Copernicus Value (2013): 6.14 | Impact Factor (2015): 6.391

- The equilibration time of the dissociation reaction of the iron sulphate is proportional to the concentration of phosphoric acid medium.

- The variation of the phosphoric acid content has no significant influence on the precipitated product nature.

- The precipitated structural analysis confirms the absence of iron phosphate $\left(\mathrm{Fe}_{3}\left(\mathrm{PO}_{4}\right)_{2}\right)$ and the compound obtained is always iron sulfates $\left(\mathrm{FeSO}_{4}\right)$.

\section{References}

[1] Antoinette Arlow (2003) Crystallisation aspects of the wet-process phosphoric acid industry.

[2] Ahlem Bendada Etude Expérimentale Et Modélisation De L'elimination Des Cations Métalliques De L'acide Phosphorique Issu Du Procédé Humide. Application Aux Cas De L'aluminium, Le Fer Et Le Cuivre 2005

[3] C. LOUIS et J. BESSIER.CAN . J . Chem. 64, 608 (19 86). Propriétés des solutions Concentrées en Acide Phosphorique.

[4] Mme Ratiba BOUSSEN Valorisation De L'acide Phosphorique Par Précipitation Du Cadmium Et Pertraction De L'uranium 2007

[5] S.ELJAOUAHRI Study Of Solubility And Speciation Of Iron Sulfates In Phosphoric Acid Milieu 2015 